\title{
Mimic high lateral myocardial infarction in chest tetany with mirror electrocardiographic change, Movable phenomenon (Yasser's phenomenon), and coronary spasm; dramatic Oxygen reversal
}

Yasser Mohammed Hassanain Elsayed ${ }^{1 *}$

${ }^{1}$ Critical Care Unit, Damietta Health Affairs, Egyptian Ministry of Health (MOH), Damietta, Egypt

*Corresponding author: Yasser Mohammed Hassanain Elsayed, Critical Care Unit, Damietta Health Affairs, Egyptian Ministry of Health (MOH), Damietta, Egypt.

Received Date: June 25, 2021; Accepted Date: July 09, 2021; Published Date: July 14, 2021

Citation: Y M H Elsayed. (2021) Mimic high lateral myocardial infarction in chest tetany with mirror electrocardiographic change, Movable phenomenon (Yasser's phenomenon), and coronary spasm; dramatic Oxygen reversal. Cardiology Research and Reports. 3(3): Doi:10.31579/26929759/025

Copyright: (c) 2021 Yasser Mohammed Hassanain Elsayed. This is an open-access article distributed under the terms of the Creative Commons Attribution License, which permits unrestricted use, distribution, and reproduction in any medium, provided the original author and source are credited.

\footnotetext{
Abstract

Rationale: Tetany is a common, serious, well-established endocrinal and metabolic hypocalcemic disorder. Chest tetany is a novel metabolic term in hypocalcemia characterized by acute severe twisting chest pain. Movable phenomenon (Yasser's phenomenon) is a new phenomenon that is usually associated with hypocalcemia. oxygenation may have a role in the management of coronary artery spasm.

Patient concerns: A middle-aged farmer smoker male patient presented to physician outpatient clinic with tetany, mimic high lateral myocardial infarction, mirror electrocardiographic change, Movable phenomenon (Yasser's phenomenon), and coronary artery spasm.

Diagnosis: Mimic high lateral myocardial infarction in chest tetany with mirror electrocardiographic change, Movable phenomenon (Yasser's phenomenon), and coronary artery spasm.

Interventions: Electrocardiography, oxygenation, IV calcium injection, and echocardiography. Outcomes: Acute dramatic clinical and electrocardiographic improvement had happened.

Lessons: The reversal of mirror electrocardiographic change, reversal of ST-segment depression coronary artery spasm, and normalization of Movable phenomenon (Yasser's phenomenon) after oxygenation. It signifies the role of oxygen in both coronary artery spasm and tetany. Mirror local electrocardiographic change is a novel described expression that may reflect the myocardial polarity in this chest tetany.

Keywords: mimic high lateral myocardial infarction; chest tetany, mirror electrocardiographic change; movable phenomenon (yasser's phenomenon); coronary spasm; oxygen reversal
}

\section{Abbreviations}

CAS: Coronary artery spasm

D1: First diagonal branch

ECG: Electrocardiography

HL-STEMI: High lateral ST-segment elevation myocardial infarction

IHD: Ischemic heart disease
MI: Myocardial infarction

NSR: Normal sinus rhythm

O2: Oxygen

PG: Prostaglandin

POC: Physician outpatient clinic

SAF: South African flag 


\section{STEMI: ST-segment elevation myocardial infarction}

TXA2: Thromboxane A2

VR: Ventricular rate

\section{Introduction}

A high lateral ST-segment elevation myocardial infarction (HLSTEMI) is a distinct tiny infarction. HL-STEMI is a pattern of STsegment elevation caused by acute occlusion of the first diagonal branch (D1) of the left anterior descending coronary artery (LAD-D1). The site of the most wonderful ST-segment deviations semblance a shape of the South African flag (SAF). A HL-STEMI is mostly named as SAF sign [1]. SAF sign is deemed a good teaching tool for easier recognition of HL-STEMI. High lateral-STEMI can present as STEMI affecting lead I and aVL. Subtle ST-segment elevation in V5, V6, and reciprocal changes in lead III and aVF may be present [1]. The twisting chest pain and its limited disappearance immediately after calcium gluconate injection indicate the pain can be named as "chest tetany" [2]. Reciprocal STdepression in the electrocardiograms (ECGs) of patients with STelevation myocardial infarction (STEMI) results from either true ischemia at a distance via collateral circulation diverting blood to the infarcted region with an electrical phenomenon that results from a mirror reflection of ST-elevation [3].

The presence of a changeable Wavy triple electrocardiographic (ECG) sign in ECG leads [4] is a hallmark for the existence of the Movable phenomenon or Yasser's phenomenon of hypocalcemia [5]. The spontaneous evanescence of Wavy triple electrocardiographic sign from affected ECG leads in serial tracings is a hallmark for the existence of the Movable-weaning phenomenon of hypocalcemia. Tachypnea was a possible cause of hypocalcemia and subsequent Wavy triple electrocardiographic and Movable-weaning phenomenon of hypocalcemia $[4,5]$.

Wavy triple an electrocardiographic sign (Yasser Sign) is a new innovated diagnostic sign in hypocalcemia [4]. The analysis for this sign in the author interpretations are based on the following;

1. Different successive three beats in the same lead are affected.

\section{All ECG leads can be implicated.}

3. An associated elevated beat is seen with the first of the successive three beats, a depressing beat with the second beat, and an isoelectric STsegment in the third one.

4. The elevated beat is either accompanied by ST-segment elevation or just an elevated beat above the isoelectric line.

5. Also, the depressed beat is either associated with ST-segment depression or just a depressing beat below the isoelectric line.

6. The configuration for depressions, elevations, and isoelectricities of ST-segment for the subsequent three beats are variable from case to case. So, this arrangement non-conditional.

7. Mostly, there is no participation among the involved leads. The author intended that is not conditionally included in an especial coronary artery for the affected leads.

Coronary artery spasm (CAS) has a remarkable role in the pathogenesis of ischemic heart disease (IHD) like angina pectoris, MI, and sudden cardiac death [6]. A reduced oxygen (O2) supply to the heart causes coronary vasodilatation (VD). However, if there are severe and prolonged hypoxia, the VD passes off and CAS results causing a vicious circle with a further decrease of myocardial oxygenation [7]. Coronary VD is caused by a reduced $\mathrm{O} 2$ supply to the heart. If the hypoxia is severe or prolonged, CAS results due to an over-decreasing of myocardial oxygenation. $\mathrm{O} 2$ may stimulate the production of thromboxane A2 (TXA2) and decreasing the syntheses of vasoconstrictor prostaglandins (PGs); the opposite effect is achieved with smoking due to the release of carboxyhemoglobin $(\mathrm{COHb}) . \mathrm{O} 2$ may increase TXA2 production and reduce the formation of vasoconstrictor PGs, while smoking, due to the formation of carboxyhemoglobin, may have the reverse effect [7]. Emotional stress, anger, and fear are leading substratum for the attacks [6]. The sublingual giving of nitrate promptly alleviates the attack but long-acting $\mathrm{Ca}^{2+}$ channel blockers (CCBs) are very effective for this condition [6].

\section{Case presentation}

A 54-year-old married farmer Egyptian heavy smoker male patient presented to the physician outpatient clinic (POC) with acute severe chest pain, carpopedal spasm, tachypnea, and palpitations. Numbness and paraesthesia in both extremities and perioral area were associated symptoms. He described the chest pain as a twisting agonizing pain. $\mathrm{He}$ gave a recent history of marked psychological stress. Informed consent was taken. Upon general physical examination; generally, the patient was tachypneic, distressed, with a regular pulse rate VR of 104, blood pressure (BP) of $150 / 90 \mathrm{mmHg}$, respiratory rate of $32 \mathrm{bpm}$, the temperature of 36.5 ${ }^{\circ} \mathrm{C}$, and pulse oximeter of oxygen $(\mathrm{O} 2)$ saturation of $96 \%$. He seemed thin and long. No more relevant clinical data were noted during the clinical examination. The patient was treated at the physician outpatient clinic (POC) with was treated with $\mathrm{O} 2$ inhalation by $\mathrm{O} 2$ cylinder $(100 \%$, by nasal cannula, $5 \mathrm{~L} / \mathrm{min}$ ). RBS was; $117 \mathrm{mg} / \mathrm{dl}$. Ionized calcium was mildly low; $0.65 \mathrm{mmol} / \mathrm{L}$. The troponin test had become negative. Serial ECG tracings were done. The initial ECG was done on presentation showing sinus tachycardia of VR; $105 \mathrm{bpm}$ with ST-segment elevations, pathological Q, and T-wave inversion in high lateral leads (I and aVL). There are a wavy triple sign or Yasser's of hypocalcemia in all ECG leads (Figure 1A) The second tracing was taken within 1 minute of the first tracing showing normal sinus rhythm (NSR) of VR; 96 bpm with STsegment elevations, pathological $\mathrm{Q}$ and $\mathrm{T}$-wave inversion in high lateral leads (I and aVL). There is a wavy triple sign or Yasser's of hypocalcemia in V1-6 leads. There are also ST-segment depressions in inferior leads (II, III, and aVF; dark blue arrows) (Figure 1B). The third tracing was taken within 2 minutes of the first tracing showing NSR of VR; $97 \mathrm{bpm}$ with ST-segment elevations, pathological $\mathrm{Q}$, and T-wave inversion in high lateral leads (I and aVL). There is a wavy triple sign or Yasser's of hypocalcemia in V1, 2, and V6 leads. There are also ST-segment depressions in inferior leads (II, III, and aVF), in anterior leads (V3-5 leads) (Figure 1C). The fourth tracing was taken within 3 minutes of the first tracing showing NSR of VR; $88 \mathrm{bpm}$ with ST-segment elevations, pathological Q, and T-wave inversion in high lateral leads (I and aVL). There is a wavy triple sign or Yasser's of hypocalcemia in V1, 4, 5, and V6 leads. There are also ST-segment depressions in inferior leads (II, III, and aVF) and Tee-Pee sign in V4 (Figure 1D). The fifth tracing was taken within 4 minutes of the first tracing showing NSR of VR; $90 \mathrm{bpm}$ with ST-segment elevations, pathological $\mathrm{Q}$, and T-wave inversion in high lateral leads (I and aVL). There is a wavy triple sign or Yasser's of hypocalcemia in V1, 3, and V4 leads. There are also ST-segment depressions in inferior leads (II, III, and aVF), in anterior leads (V5 and V6 leads) (Figure 1E). Echocardiography was done on the third day of the presentation showing mild diastolic dysfunction with an EF of $67 \%$ (Figure 2). Mimic HL-STEMI in chest tetany with mirror ECG change, 
Movable phenomenon (Yasser's phenomenon), and CAS was the most probable diagnosis. ECG tracing was taken within 40 minutes of the first ECG tracing and 20 minutes of $\mathrm{O} 2$ inhalation showing normalization of above Wavy triple sign of hypocalcemia and ST-segment depressions. But there is a reversal of pathological Q, in I and aVL leads to be S-waves and normalization of ST-segment elevations in the same leads with NSR

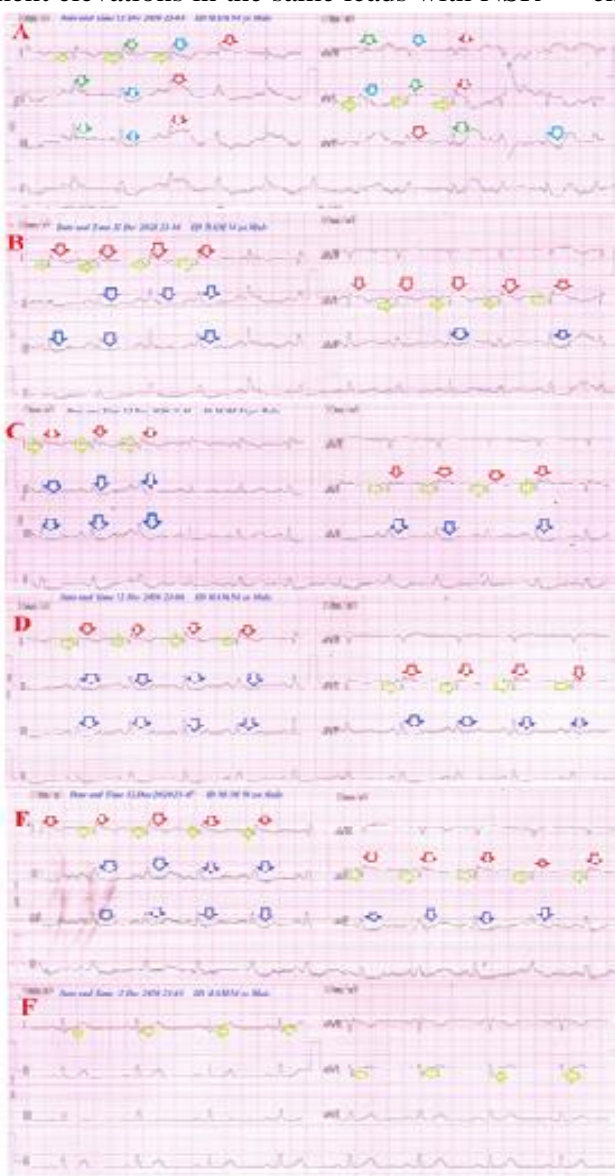

of VR 67 (Figure 1F). Within 40 minutes of the above management, the patient finally showed nearly complete clinical and ECG improvement. Then, two-calcium gluconate ampoules (10ml 10\%) over IV over 20 minutes was given. The patient was continued on oral calcium, and vitamin-D preparation for 30 days with further advised cardiac and endocrinal follow-up.

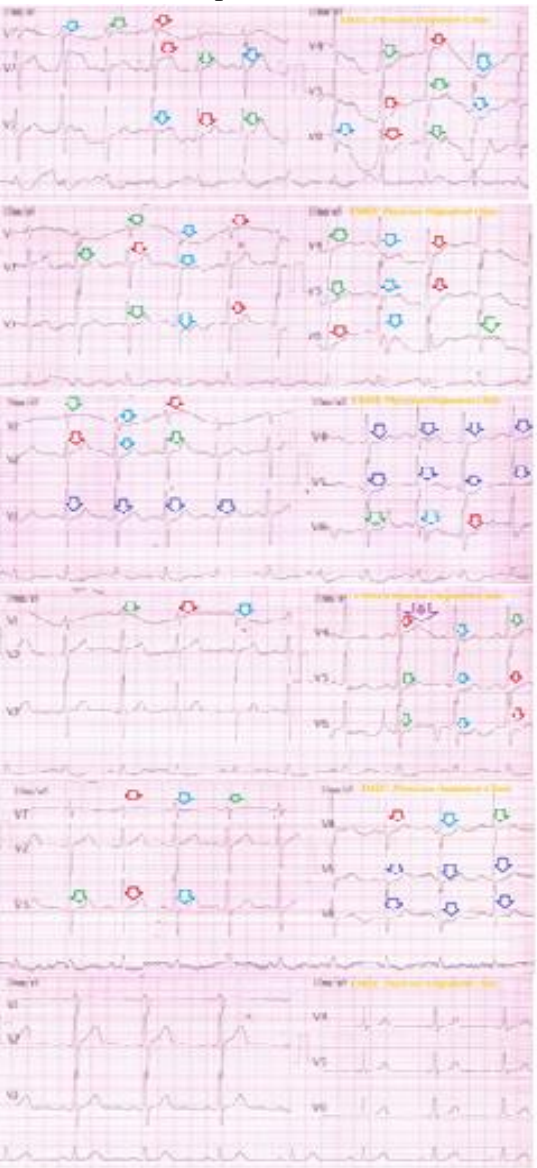

Figure 1: Serial ECG tracings.

A. tracing was done on the initial ECG on presentation showing sinus tachycardia of VR; 105 bpm with ST-segment elevations, pathological $\mathrm{Q}$ (lime arrows), and T-wave inversion in high lateral leads (I and aVL). There is a wavy triple sign or Yasser's of hypocalcemia in all ECG leads (red, green, and blue arrows).

B. tracing was taken within 1 minute of tracing-A showing NSR of VR; 96 bpm with ST-segment elevations (red arrows), pathological Q (lime arrows), and T-wave inversion in high lateral leads (I and aVL). There is a wavy triple sign or Yasser's of hypocalcemia in V1-6 leads (red, green, and blue arrows). There are also ST-segment depressions in inferior leads (II, III, and aVF; dark blue arrows).

C. tracing was taken within 2 minutes of tracing-A showing NSR of VR; 97 bpm with ST-segment elevations (red arrows), pathological Q (lime arrows), and T-wave inversion in high lateral leads (I and aVL). There is a wavy triple sign or Yasser's of hypocalcemia in V1, 2, and V6 leads (red, green, and blue arrows). There are also ST-segment depressions in inferior leads (II, III, and aVF; dark blue arrows), in anterior leads (V3-5 leads; dark blue arrows).

D. tracing was taken within 3 minutes of tracing-A showing NSR of VR; 88 bpm with ST-segment elevations (red arrows), pathological Q (lime arrows), and T-wave inversion in high lateral leads (I and aVL). There is a wavy triple sign or Yasser's of hypocalcemia in V1, 4, 5, and V6 leads (red, green, and blue arrows). There are also ST-segment depressions in inferior leads (II, III, and aVF; dark blue arrows) and Tee-Pee sign in V4 (double pink arrow).

E. tracing was taken within 4 minutes of tracing-A showing NSR of VR; 90 bpm with ST-segment elevations (red arrows), pathological Q (lime arrows), and T-wave inversion in high lateral leads (I and aVL). There is a wavy triple sign or Yasser's of hypocalcemia in V1, 3, and V4 leads (red, green, and blue arrows). There are also ST-segment depressions in inferior leads (II, III, and aVF; dark blue arrows), in anterior leads (V5 and V6 leads; dark blue arrows).

F. tracing was taken within 40 minutes of the first ECG tracing and 20 minutes of $\mathrm{O} 2$ inhalation showing normalization of above Wavy triple sign of hypocalcemia and ST-segment depressions. But there is a reversal of pathological Q in I and aVL leads to be S- waves and normalization of ST-segment elevations in the same leads with normal sinus rhythm of VR 67. 


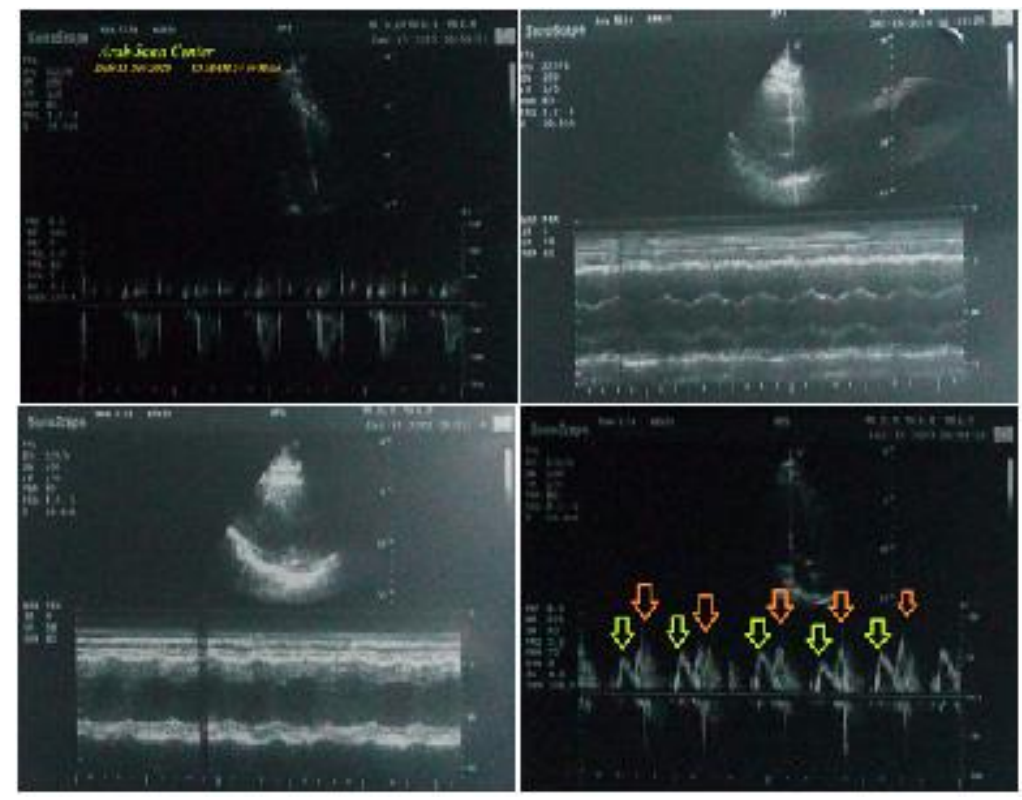

Figure 2: Echocardiography was done on the third day of the presentation showing mild diastolic dysfunction (lime and orange arrows) with an EF of $67 \%$.

\section{Discussion}

\section{- Overview:}

- A middle-aged farmer smoker male patient presented to physician outpatient clinic with tetany, mimic high lateral myocardial infarction, mirror electrocardiographic change, Movable phenomenon (Yasser's phenomenon), and coronary artery spasm.

- The objective primary for my case study was the presence of tetany, mimic high lateral myocardial infarction, mirror electrocardiographic change, Movable phenomenon (Yasser's phenomenon), and coronary artery spasm in POC.

- The secondary objective for my case study was the question of; How did you manage the case?

- Severe emotional stress and heavy cigarette smoking are the main risk factors for both coronary artery spasm and the Movable-weaning phenomenon of hypocalcemia in the current case study.

- The presence of mimic HL-STEMI then reversible mirror ECG change are unknown-prescribed in the past literature.

- Flag-South-Africa configuration for is a hallmark for high lateral STEMI (Figure 3A).

- The presence of ST-segment depressions in ECG may be interpreted as accompanied by severe specific ischemic myocardial insult.

- The change in myocardial polarity is a highly suggestive interpretation for both mimic HL-STEMI and reversible mirror ECG change (Figure 3B).
- The dramatic reversal of ST-segment depressions in ECG may be interpreted as a coronary artery spasm.

- Hypoxia was a possible mechanism.

- There is a dramatic reversal of ST-segment depressions coronary artery spasm post-oxygenation.

- The spontaneous evanescence of Wavy triple electrocardiographic sign from affected ECG leads in serial tracings is a hallmark for the existence of the Movable-weaning phenomenon of hypocalcemia. Tachypnea or hyperventilation is a possible cause of hypocalcemia and subsequent Wavy triple ECG and Movable-weaning phenomenon of hypocalcemia $[4,5]$.

- An associated transient "Tee-Pee Sign" may be indicating severe hypocalcemia. The T-wave that interlocking the $\mathrm{U}$-wave was the result that is called the "Tee-Pee Sign" due to the shape of the QRS-complexes like the conventional fashion of Native American Indians dwelling [2].

- An accompanied chest tetany is evidence of severe hypocalcemia.

- Negative troponin test, normal echocardiography, and rapidly reversible changes of mimic HL-STEMI are against the diagnosis of true acute myocardial infarction and IHD.

- I can't compare the current case with similar conditions. There are no similar or known cases with the same management for near comparison.

- The only limitation of the current study was the unavailability of the invasive test for coronary artery spasm. 


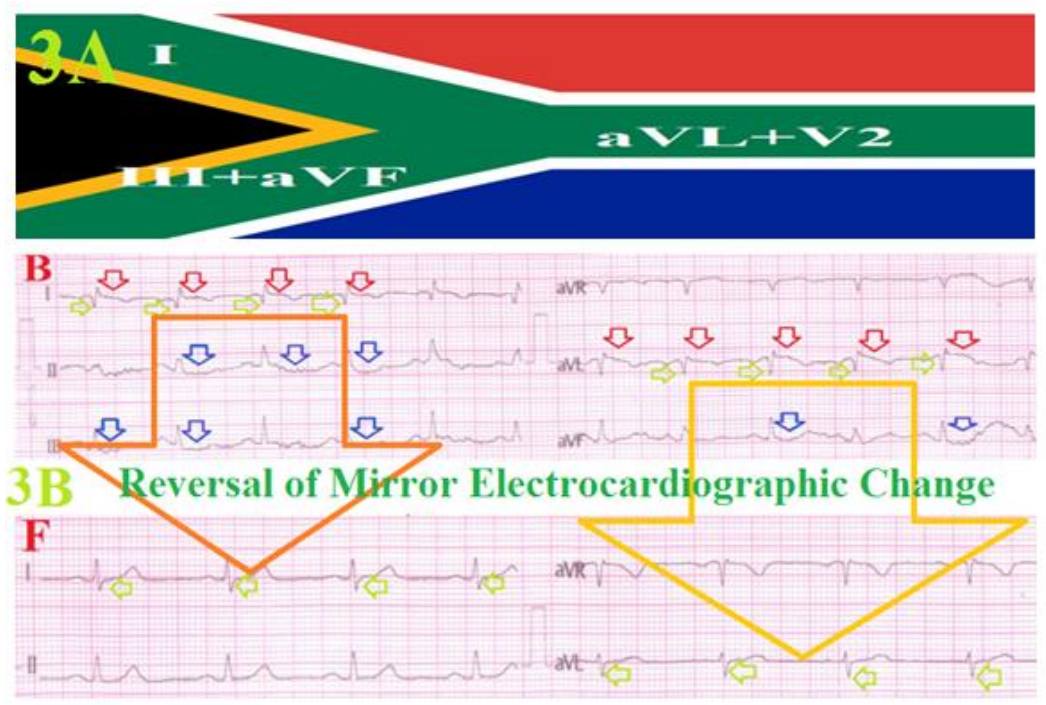

Figure; 3A: Diagram showing Flag-South-Africa configuration for high lateral STEMI1. 3B- ECG tracings are showing a shortcut of reversal of mirror electrocardiographic change for the second tracing (B) and the last one (F).

\section{Conclusion and Recommendations}

- The reversal of mirror electrocardiographic change, reversal of STsegment depression coronary artery spasm, and normalization of Movable phenomenon (Yasser's phenomenon) after oxygenation.

- It signifies the role of oxygen in both coronary artery spasm and tetany.

- Mirror local electrocardiographic change is a novel described expression that may reflect the myocardial polarity in this chest tetany.

\section{Conflicts of interest}

- There are no conflicts of interest.

\section{Acknowledgment}

- I wish to thanks my wife to save time and improving the conditions for helping me.

\section{References}

1. Elsayed YMH. (2019) High lateral myocardial infarction: the smallest but the most painful infarction - a case report. Asclepius Med Res Rev.2(2):1-4.
2. Elsayed YMH. (2020) Hypocalcemia-induced Camel-hump Twave, Tee-Pee sign, and bradycardia in a car-painter of a complexed dilemma: A case report. Cardiac; 2(1):1-5.

3. Vaidya GN, Antoine S, Imam SH, Kozman H, Smulyan H, Villarreal D. (2018) Reciprocal ST-Segment Changes in Myocardial Infarction: Ischemia at Distance Versus Mirror Reflection of ST-Elevation. Am J Med Sci. Feb. 355(2):162-167.

4. Elsayed YMH. (2019) Wavy Triple an Electrocardiographic Sign (Yasser Sign) in Hypocalcemia. A Novel Diagnostic Sign; Retrospective Observational Study. EC Emergency Medicine and Critical Care (ECEC).3(2):1-2.

5. Elsayed YMH. (2021) Movable-Weaning off an Electrocardiographic Phenomenon in Hypocalcemia (Changeable Phenomenon or Yasser's Phenomenon of Hypocalcemia)Retrospective-Observational Study. CPQ Medicine, 11(1), 01-35.

6. Yasue H, Mizuno Y, Harada E. (2019) Coronary artery spasm Clinical features, pathogenesis and treatment. Proc Jpn Acad Ser B Phys Biol Sci. 95(2):53-66.

7. Karmazyn M, Manku MS, Horrobin DF. (1979) The mechanism of coronary artery spasm: roles of oxygen, prostaglandins, sex hormones and smoking. Med Hypotheses.5(4):447-452. (c) (P) This work is licensed under Creative Commons Attribution 4.0 License

To Submit Your Article Click Here: Submit Manuscript

DOI: $10.31579 / 2692-9759 / 025$
Ready to submit your research? Choose Auctores and benefit from:

* fast, convenient online submission

* rigorous peer review by experienced research in your field

* rapid publication on acceptance

* authors retain copyrights

* unique DOI for all articles

* immediate, unrestricted online access

At Auctores, research is always in progress.

Learn more www.auctoresonline.org/journals/cardiology-research-andreports- 